\title{
Politique
}

Politique

\section{Alfred O. Hero, jr., Marcel Daneau et collaborateurs, Problems and Opportunities in U.S.-Quebec Relations, Boulder, Col., Westview, 1984, 320 p.}

\section{François-Pierre Gingras}

Numéro 7, hiver 1985

Projection internationale du Québec

URI : https://id.erudit.org/iderudit/040484ar

DOI : https://doi.org/10.7202/040484ar

Aller au sommaire du numéro

Éditeur(s)

Société québécoise de science politique

ISSN

0711-608X (imprimé)

1918-6584 (numérique)

Découvrir la revue

Citer ce compte rendu

Gingras, F.-P. (1985). Compte rendu de [Alfred O. Hero, jr., Marcel Daneau et collaborateurs, Problems and Opportunities in U.S.-Quebec Relations, Boulder, Col., Westview, 1984, 320 p.] Politique, (7), 120-122.

https://doi.org/10.7202/040484ar d'utilisation que vous pouvez consulter en ligne.

https://apropos.erudit.org/fr/usagers/politique-dutilisation/ 
Alfred O. Hero, jr., Marcel Daneau et collaborateurs, Problems and Opportunities in U.S. - Quebec Relations, Boulder, Col., Westview, $1984,320 \mathrm{p}$.

Les rapports entre le Québec et les États-Unis n'ont pas fait l'objet d'un grand nombre d'analyses. Il faut savoir gré au Centre québécois de relations internationales (à l'Université Laval), à la World Peace Foundation de Boston et au University Consortium for Research on North America (logé à l'Université Harvard) d'avoir encouragé des chercheurs à explorer des pistes relativement peu fréquentées jusqu'ici. Le recueil Problems and Opportunities in U.S.-Quebec Relations s'inscrit dans une foulée d'ouvrages où des analystes des deux côtés de la frontière apportent des éléments de description et d'interprétation sur des questions «of mutual interest» (p. xiii). Inutile de chercher une vision d'ensemble chez les quinze auteurs rassemblés par Alfred Hero et Marcel Daneau. Néanmoins, on retrouve en fin de volume une synthèse et des «recommandations» qui méritent l'attention des lecteurs et lectrices.

Après une brève introduction, le recueil s'ouvre sur des textes traitant des relations économiques. Bernard Bonin se penche 
sur les échanges commerciaux et les investissements et aborde de façon spécifique l'attitude "dirigiste» du gouvernement péquiste face aux entreprises multinationales; l'ex-sous-ministre québécois aujourd'hui professeur à l'ÉNAP conclut que le Québec n'est finalement que l'un des nombreux états-nations prostitués qui sollicitent, tout en le haïssant, le capitalisme international. Sur un ton racoleur, Jean Bovin cherche à convaincre les investisseurs américains que, malgré sa spécificité sociopolitique, le Québec est une valeur sûre: les syndicalistes radicaux ont de grandes gueules mais les bons syndiqués sont «basically oriented toward 'bread and butter' issues rather than ideologies» (p. 62); d'ailleurs, le gouvernement du Parti québécois a su se montrer très ferme avec les syndicats du secteur public, alors que dans le secteur privé (et surtout les industries de pointe) le mouvement syndical tire de l'aile. Mais il y a beaucoup à faire pour venir à bout des impressions plutôt négatives du banquier Alexander Tomlinson: non seulement énumère-t-il plus d'obstacles que d'incitations aux investissements américains, mais encore termine-t-il son court bilan en exprimant ses craintes face aux perspectives d'instabilité politique au Québec (les velléités séparatistes du premier ministre Lévesque, vous connaissez?). Enfin, Réjean Lachapelle trace le portrait des mouvements démographiques entre le Québec et les États-Unis depuis le dix-neuvième siècle, alors que John E. Carroll fait ressortir les intérêts communs du Québec et des états du Nord-Est en matière d'environnement: il s'agit de deux textes passablement rigoureux.

Les rapports "culturels» occupent eux aussi cinq chapitres, fort inégaux mais tous intéressants, notamment l'analyse d'Yvan Lamonde et les réflexions de Stephen Baker sur le rôle des médias dans l'évolution des valeurs des Québécois et dans l'image du Québec diffusée aux Américains. Cette image fait aussi l'objet d'un texte de Martin Lubin sur le renforcement mutuel des perceptions anglo-québécoises et américaines à l'égard d'un Québec 
dont le nationalisme d'après 1976 inquiète et dérange. Deux chapitres traitent de l'héritage francophone en Nouvelle-Angleterre et en Louisiane.

Au sens étroit du terme, la dimension proprement politique des relations Québec-États-Unis occupe peu d'espace (deux chapitres) mais couronne vraiment le recueil. Louis Balthazar examine le contexte (vu de Québec, bien sûr) des rapports entre les deux sociétés, distingue les intérêts qui s'en dégagent pour nous et les politiques qui y correspondent, pour terminer par les contraintes auxquelles le gouvernement doit faire face; c'est une analyse très pertinente émaillée des prédictions de l'auteur quant à l'attitude du gouvernement Mulroney face aux intérêts du Québec (on notera qu'au moment où cet article fut écrit, Pierre Elliot Trudeau n'avait pas encore démissionné!). En parallèle, Charles Doran et Brian Job tentent de dégager, de façon fort systématique, la perspective adoptée à Washington à l'égard du Québec; que trouvent-ils? «A policy of having no policy» (p. 270). Pourquoi? «U.S. perceptions regarding Quebec are a mixture of ignorance, esteem, curiosity, and benevolence.» (p. 271).

Sans doute trouvera-t-on cette recension très descriptive et peu critique. En effet, comme on trouvera dans le recueil de Hero et Daneau peu de théorie et beaucoup de perceptions. À ce titre, on ne lira pas ce livre d'abord pour augmenter nos connaissances objectives sur les relations Québec-États-Unis, mais plutôt pour s'en faire une image. De ce point de vue, l'effort des initiateurs est méritoire.

François-Pierre Gingras Université d'Ottawa 